\title{
Secondary pre-service teachers' perceptions of technological pedagogical content knowledge (TPACK): What do they really think?
}

\author{
Petrea Redmond \\ University of Southern Queensland \\ Jennifer Lock \\ University of Calgary
}

\begin{abstract}
Meaningful integration of digital technology into learning and teaching is ill-structured, complex, and messy. Inherent in the complexity is the interaction between the different domains of teacher knowledge. The multifaceted problem is further compounded by the diversity of learners and technology in today's dynamic classroom contexts. Pre-service teachers often feel ill-prepared to plan for effective technology integration in their classrooms. Technological pedagogical content knowledge (TPACK) has provided educators with a theoretical framework to unpack the complexity of technology integration. It sits at the heart of three interrelated components: content knowledge, pedagogical knowledge, and technological knowledge. These knowledge areas interact, support, and constrain each other. This study investigated secondary pre-service teachers' perceptions of TPACK. Data were collected through an online survey and interviews. Following a brief introduction to TPACK, this article explores secondary pre-service teachers' perceptions of TPACK and its components, along with their professional learning needs for TPACK development. Implications for teacher education programs are also provided.
\end{abstract}

\section{Introduction}

Effective teaching with information communication technology (ICT) becomes more challenging as new technological devices and tools become available. ICT integration has been acknowledged as "complex, multifaceted, and situated” (Mishra \& Koehler, 2006, p. 1017). It is difficult for educators to be familiar with the growing number of ICT tools which are now available, and then consider how they may use these items in the most effective and productive way in support of learning and teaching. To aid educators' development of ICT integration, researchers and practitioners develop models of required knowledge for teachers, and how they apply such knowledge to their own learning and teaching contexts.

There are countless frameworks that investigate in-service and pre-service teachers (PST) knowledge, mastery, and use of technology for teaching and learning purposes. Examples of these models that support or enable educators to design, develop, and infuse digital learning experiences include RAT, SAMR, TIM, and TPACK. The replacement, amplification, transformation (RAT) model developed by Hughes (2005) can be used to inform "critical decision-making concerning integration of technology into the K-12 classroom” (Hughes, Thomas, \& Scharber, 2006, p. 1616). The SAMR model (Puentedura, 2014), is thought to build on the RAT model (Green, 2014), and provides a model for technology integration at different levels through substitution, augmentation, modification, and redefinition. However, little peer reviewed work has been published that provides a theoretical grounding for the SAMR Model.

The technology integration matrix (TIM) (Florida Center for Instructional Technology, 2005-2018) provides a framework for planning for the use of technology to enhance learning. TIM includes a matrix including five interdependent elements: active, collaborative, constructive, authentic, and goal-directed. These are also associated with five commonly presented levels of technology integration: entry, adoption, adaptation, infusion, and transformation.

The technological pedagogical content knowledge (TPACK) (Koehler \& Mishra, 2005a, 2005b) theoretical framework builds on Shulman's (1986) concept of pedagogical content knowledge. TPACK presents seven interrelated knowledge types essential to teachers in today's digital world. These distinct forms of teacher 
knowledge come from three core components: (1) pedagogical knowledge (PK); (2) content knowledge (CK), and (3) technological knowledge (TK). These are then combined to create four new types of knowledge: (1) pedagogical content knowledge (PCK); (2) technological pedagogical knowledge (TPK); (3) technological content knowledge (TCK); and (4) technological pedagogical content knowledge (TPACK), which should then be viewed within the learning and teaching context. TPACK has been embraced by teacher educators for research and teaching purposes.

The purpose of this article it is to examine PSTs' perceptions of TPACK within a secondary context. Unlike most TPACK research, this study does not measure TPACK, nor is it located in an elementary context. Using a qualitative approach, this study explores secondary PSTs' descriptions of TPACK and its components, along with their experiences within their teacher education program and their professional experience placements.

\section{TPACK}

TPACK is "achieved when a teacher knows how technological tools transform pedagogical strategies and content representations for teaching specific topics” (Jang, 2010, p. 1744). According to Harris and Hofer (2011), "TPACK as it is applied in practice must draw from each of its interwoven aspects, making it a complex and highly situated educational construct that is not easily learned, taught, or applied” (p. 213). An understanding of the intricate relationships between technology, pedagogy and content knowledge result in the development of unique learning experiences. The different components for TPACK and the TPACK construct itself are briefly described in Table 1.

Table 1

Components of the TPACK model

\begin{tabular}{|c|c|}
\hline Construct & Definition \\
\hline CK & $\begin{array}{l}\text { Teachers’ knowledge about the subject matter to be learned or taught. ... As Shulman } \\
\text { (1986) noted, this knowledge would include knowledge of concepts, theories, ideas, } \\
\text { organizational frameworks, knowledge of evidence and proof, as well as established } \\
\text { practices and approaches toward developing such knowledge. (Koehler \& Mishra, 2009, } \\
\text { p. 63) }\end{array}$ \\
\hline PK & $\begin{array}{l}\text { Teachers' deep knowledge about the processes and practices or methods of teaching and } \\
\text { learning. They encompass, among other things, overall educational purposes, values, and } \\
\text { aims. This generic form of knowledge applies to understanding how students learn, } \\
\text { general classroom management skills, lesson planning, and student assessment. (Koehler } \\
\text { \& Mishra, 2009, p. 64) }\end{array}$ \\
\hline TK & $\begin{array}{l}\text { [K]nowledge of the existence, components, and capabilities of various technologies as } \\
\text { they are used in teaching and learning settings, and conversely, knowing how teaching } \\
\text { might change as the result of using particular technologies. (Mishra \& Koehler, 2006, p. } \\
\text { 1028) }\end{array}$ \\
\hline PCK & $\begin{array}{l}\text { Consistent with and similar to Shulman's idea of knowledge of pedagogy that is } \\
\text { applicable to the teaching of specific content. Central to Shulman's conceptualization of } \\
\text { PCK is the notion of the transformation of the subject matter for teaching. Specifically, } \\
\text { according to Shulman (1986), this transformation occurs as the teacher interprets the } \\
\text { subject matter, finds multiple ways to represent it, and adapts and tailors the instructional } \\
\text { materials to alternative conceptions and students' prior knowledge. (Koehler \& Mishra, } \\
\text { 2009, p. 64) }\end{array}$ \\
\hline TCK & $\begin{array}{l}\text { Understanding the impact of technology on the practices and knowledge of a given } \\
\text { discipline is critical to developing appropriate technological tools for educational } \\
\text { purposes. The choice of technologies affords and constrains the types of content ideas } \\
\text { that can be taught. (Koehler \& Mishra, 2009, p. 65) }\end{array}$ \\
\hline
\end{tabular}




\begin{tabular}{|l|l|}
\hline TPK & $\begin{array}{l}\text { [A]n understanding of how teaching and learning can change when particular } \\
\text { technologies are used in particular ways. This includes knowing the pedagogical } \\
\text { affordances and constraints of a range of technological tools as they relate to } \\
\text { disciplinarily and developmentally appropriate pedagogical designs and strategies. } \\
\text { (Koehler \& Mishra, 2009, p. 65) }\end{array}$ \\
\hline TPACK & $\begin{array}{l}\text { Effective teaching with technology, requiring an understanding of the representation of } \\
\text { concepts using technologies; pedagogical techniques that use technologies in } \\
\text { constructive ways to teach content; knowledge of what makes concepts difficult or easy } \\
\text { to learn and how technology can help redress some of the problems that students face; } \\
\text { knowledge of students' prior knowledge and theories of epistemology; and knowledge of } \\
\text { how technologies can be used to build on existing knowledge to develop new } \\
\text { epistemologies or strengthen old ones. (Koehler \& Mishra, 2009, p. 66) }\end{array}$ \\
\hline
\end{tabular}

\section{Method}

This research used a naturalistic inquiry approach (Lincoln \& Guba, 1985) to explore secondary PST's perceptions of TPACK. The following characteristics of the naturalistic inquiry were found in this research. The research studied a real-world situation without any manipulation or control. It was completed in a natural setting, with the researchers as human instruments bringing background knowledge to the research, reporting the outcomes as a case study, and making tentative conclusions (Lincoln \& Guba, 1985). The researchers used two data sources. First, after ethical clearance PSTs were invited to complete an online survey with six open ended questions about their knowledge, experience, and perceptions of TPACK and its elements. The survey asked them to identify specific examples of where they have seen TPACK modelled either in their education courses, discipline courses or while on professional experience, along with examples of how they have demonstrated their understanding of TPACK in their course work or on professional experience. Second, PSTs were invited to participate in a 20-minute interview to explore their ideas in greater depth. They were asked to respond to such questions as: Describe your competence and confidence with TK? How do you see your professional experience placement contributing to your development of TPACK?

The PST participants were studying in a regional university in Australia. They were either in their second year of a 4-year initial teacher education program or the first semester of a 1-year Graduate Diploma of Education. Ninety-seven PSTs (83\% of the cohort) completed the survey and 15 were interviewed.

A constant comparison approach was used to identify patterns and outliers in the survey and interview data to create categories and common themes. This inductive analysis of the data explored the repetition of words and concepts, along with similarities and differences between responses (Ryan \& Bernard, 2003). Initially, the themes were aligned with each of the components of TPACK (i.e., CK, PK, TK, PCK, TCK, TPK) to explore the PSTs' knowledge and understanding of TPACK. A cutting and sorting (Lincoln \& Guba, 1985) process of refinement resulted in further data themes which aligned specific with the preservice teachers' ongoing learning needs.

This qualitative study was guided by the following research questions:

- What are secondary PSTs' perceptions of TPACK?

- What are secondary PSTs' perceived learning needs to develop TPACK?

\section{Findings and discussion}

The findings present the PSTs' perceptions of each component of TPACK along with their own professional learning needs for TPACK development. Each of the following sections is presented with representative quotes from the PST online survey and interviews. 
Perceptions of the elements of TPACK

From the data, it appears that PSTs have a positive attitude towards TPACK. They see technology as a tool where "anything is possible as long as the teacher provides the opportunities and has an open mind and is willing to go the extra mile to support their students!” (PST AA). PSTs were asked what is TK. PST A declared: "[T]his applies to the teacher's own knowledge of technology and their own competence and knowledge of applicable technologies". PST N exposed: "[W]ith no formal training with TK, I pretty much muddle through. You learn a lot from your kids.” When the PSTs used the term technology, they appeared to be almost exclusively referring to information communication technologies without an appreciation that technology could also be conceived more broadly including technology, tools and resources which can be used productively at work and in everyday life (Koehler \& Mishra, 2009). The authors also acknowledged that the term technology refers to analogue and digital tools and that "TK is always in a state of flux" (Koehler \& Mishra, 2009, p. 64). In addition, there was also recognition that sometimes there may be a mismatch of technologies in what they had previously learned and what was now being used in schools. An important element of the TPACK framework is the acknowledgement of the continuous change with regard to emerging technologies. "As new technology emerges and is used in classrooms, effective teachers will incorporate the technology through TPACK” (Hilton, 2016, p. 70). This ability to effectively integrate the technology may take time and will require support. The ability to learn and try out things in an informed manner becomes a critical factor when using TPACK. "There is more to teacher preparation than training teachers how to use tools - it requires appreciation of the complex set of interrelationships between artefacts, users, tools, and practices" (Koehler \& Mishra, 2005b, p. 96).

PST B suggested CK "relates to your syllabus and knowing what you are going to teach to the children" and that it was essential to "feel confident and competent". Whereas, PST M perceived the CK was "the curriculum - the knowledge required by a teacher to provide students with the requisite knowledge for their particular subject”. PSTs with an industry background or broader life experience appeared more confident of their understanding of CK. There was an acknowledgement that: "You have to know what you are talking about" (PST A), and that "it was very important to have a good grasp of the theory behind you" and "feel confident" (PST J). The PSTs were more cautious about expressing a level of confidence when teaching senior classes (Year 11/12). Comprehensive content knowledge was identified by Starkey (2010) as one of the building block of teachers' knowledge and the PSTs' perceptions of content knowledge include those established in the literature including the "central theories and concepts of topics taught" and "an understanding of the nature of the knowledge and the means of inquiry in the field" (Valtonen et al., 2017, p. 16).

PK was perceived by PST M as the "tools and the processes by which the teacher extends their knowledge to the students". In contrast PST A commented that it was "[k]nowing how kids learn". Valtonen et al. (2017) described PK as "an understanding of learning processes and the ability to control and guide the learning situation" (p. 16) and includes knowledge about cognition and generic theories of learning. Although at the beginning of their teacher education programs, the PSTs were beginning to make links between CK and PK. PST B suggested that PK was related to "thinking about how you can teach the content to the students so they learn best". Similarly, PST F mentioned "I think the more confident I am in the content, the better I teach it because I can handle the questions" and implement better teaching practices. PST J noted that professional experience was the key place to learn PK because "it is about practice". The PSTs' alignment of CK and PK describes Shulman's (1986) PCK construct.

PSTs saw real-life experience and professional experience placements as the key to developing strong PCK. PST B argued: "[O]bviously you need to know your content and how to teach it." PST O believed: "I feel like this is where it should be." PST C summarised other comments stating: "Pretty much all learning in this area has been on prac." Shulman (1986) described PCK as the key knowledge of teachers, it is "the ways of representing and formulating the subject that makes it comprehensible for others" (p. 9). PST F, a mature aged PST, observed that their previous experience in industry was important "so can relate real world experience to the students". Loughran, Mulhall, and Berry (2004) found that when teachers talk about PCK, they describe their practice and how it is related to content understanding. PST M indicated that in the past they had looked at teaching from a "traditional teaching sense - proven strategies, classic learning styles ... but TPACK highlights the importance of the third element (technology).” PSTs were developing a greater appreciation for how and why to integrate technology into teaching and learning. 
The PSTs spoke of TPK as a means of engaging students and providing a more relevant and flexible approach to meet learner needs. PST A proposed that TPK was "[k]nowing how your pedagogy works with your technology". This understanding aligned with PST B who believed that it was "using technology to teach the students - more like a 21st century approach." Similarly, PST M saw TPK as "the way the teacher teaches and the technology are combined" it is another way to "reach the students more effectively, for some students, this is possibly more engaging.” The PSTs also acknowledged the relationship between technology knowledge and teaching practices. For example, PST N claimed that "being competent in technology broadens the whole thing. If you are confident and know a lot about it you can branch out and try different approaches." The PSTs seemed well versed in TPK which is also supported by research examining secondary pre-service teacher reflections by Hofer and Grandgenett (2012) who found a higher number of items coded as TPK than those as TCK.

The PSTs saw TCK as a way to explore content in new and more engaging ways. They seemed confused and limited in their knowledge about this construct. Many PSTs made comments that they had used technology to find content. For example, PST C suggested that TCK is related to the fact that "most of your content is found on technology". PST G observed: "It will be a bit easier to get across content because you have all these different technologies available - interactive websites, videos etc.” From the data, there seemed little understanding of how technology and content can influence and constrain one another (Koehler \& Mishra, 2009). Further, there was no acknowledgement that content can be changed by the application of technology, nor the fact that PSTs need to have a deeper understanding about which technologies would be best to teach which content. Graham (2011) and others have noted there are a range of definitions for TCK and TPK and no clear association with each of the constructs. Koh, Chai, and Tsai (2010) also found that their participants were unable to distinguish between the constructs of TCK, TPK, and TPACK.

PST M maintained: "[O]ne of the main goals of the teacher is making the students comfortable with the content and approach to learning." PSTs saw TPACK as "combining the three elements all in one” and providing a contemporary learning environment where students are comfortable. PST N saw TPACK as "transforming the subject matter for teaching and engaging the students" and that "as teachers we need to try and use these technologies to get the content across". PST B reflected that the concept of TPACK was "embedded deep down in my mind" and that it is "the way teaching and learning is evolving”. PSTs were beginning to develop an appreciation that TPACK is greater than the sum of each of its components (Mishra \& Koehler, 2008) and its transformative nature.

\section{Professional learning needs for TPACK development}

When asked to describe their comfort level teaching with ICT there were a range of responses from very uncomfortable to very high levels of comfort. However, even those with very high levels of comfort provided examples that were limited to generic Microsoft software such as Excel, PowerPoint, Movie Maker, and finding resources on the Internet such as YouTube video's or online quizzes. PST AC astutely commented that they would "incorporate [ICTs] where required: rather than using it for its own sake". Interestingly PST G reflected: "I feel competent in my ability to use technology in the classroom but getting the students to use it will be challenging.” Whereas, PST K confessed: “[A]s far as the technology goes I am 'flying by the seat of my pants'.” Wozney, Venkatesh, and Abrami (2006) found that confidence was one of the greatest predictors of teachers' likelihood to use technology. It seems that the PST respondents were confident and willing to try new things even when they were not competent with the technology.

Pre-service teachers did indicate a steep learning curve during their education courses and in their professional experiences. PST AO mentioned having "had my eyes opened since being on prac" and PST M suggested that "knowledge will come through practical experience, feeding off the knowledge of experienced teachers". When interviewed, after their professional experience placement, the PST listed a broader range of examples such as interactive whiteboards, virtual environments, and other discipline specific examples which were previously unknown to them. PST A commented: "You learn best when you are actually teaching”. This was supported by PST J who claimed: "[I]t's practice in the classroom that really matters". Harris and Hofer's (2017) study supported this notion that TPACK should be "applied, not theoretical knowledge" (p. 11). Given the importance of practise-based learning it is not surprising that PST lamented that they "have limited opportunity to practice" with such technology. As noted by PST AF: 
[A]nything is possible ... there are limits such as whether the technology is available and accessible, whether it detracts from the actual content, how long it would take to implement, how technologically savvy the students are, the potential for cyberbullying, among others.

PSTs did acknowledge a number of areas for self-improvement. PST M noted TPACK “is always a work in progress for teachers - we come in with our degree and personal experience but in doing my pracs, I found there are a lot of teachers ... who are learning all the time.” PST AG stated: "Pedagogy changes so frequently - there is always a new and better approach". PST AK suggested: "I would like more instruction and modelling in [TPACK]”. The PSTs comments were similar to what Redmond and Brown (2004) found in their study, over a decade previously, where the teachers in their study felt like they were on a learning cliff rather than a steep learning curve.

From the data, it was evident that PSTs wanted to enhance their TPACK practice but were unsure how to proceed. When discussing strategies of improvement PST AA proffered: "I'm unsure about how far the possibilities go and I am hesitant to go very far beyond the basics right now as I would prefer to solidify my teaching skills first before becoming too involved in computer aids." When reflecting on how they can improve their TPACK knowledge, others have commented: "I think I have to do more research" (PST H), and "I am always on the lookout for resources ... using my networks, using the internet and developing my own as well” (PST N). When investigating teacher professional development in TPACK, Harris and Hofer (2017) found that it was important to ensure that professional learning was "meeting the teachers where they are” (p. 11). This has implications for teacher education to provide sustainable yet individualised ongoing professional learning.

The PSTs acknowledged specific courses and teacher educators from their teacher education program who provided explicit models and guidance in the development of TPACK. In the capstone course, the PST are required to complete an "eportfolio that demonstrated how we had satisfied the requirements of the teachers' standards. This was new technology to most PSTs, tutorials were provided to learn how to use it and a portfolio was created electronically for assessment” (PST AF). One course provided synchronous and asynchronous opportunities for online collaboration with practicing teachers. Most courses provided content using "visual, written and audio technology" and one teacher educator "consistently focused on the combination of teaching strategies alongside of ICTs and content. Every lesson that was taught by her was sufficiently detailed and acted as an excellent reminder for the implementation of these areas into our planning and teaching” (PST AK). Another PST commented: “This course teaches that knowledge is evolving and so my current knowledge of what is possible in terms of teaching with ICT depends on what is available” (PST AL). Kaufman (2015) and Tondeur, Scherer, Siddiq, and Baran (2017) found that teacher educators should act as positive role models and motivators for technology enhanced learning, providing examples is not sufficient to make sustainable change within the profession.

PSTs admitted seeing different approaches and models of TPACK while on different professional experience placements. As would be expected from secondary PSTs, the examples were mostly discipline specific examples rather than generic. For example, they reported seeing such items as "students use graphmatica to plot their graphs”, “[u]sing the TI-84 graphics calculator”, and "[u]sing a smartboard to demonstrate how to draw using AutoCAD software". The PSTs were also aware that the TPACK components including pedagogy involved deeper learning when engaged in their professional experience. PST O noted: "I think my PK is not where it should be which is why I go day a week to see and observe to see what works and what does not work. To see how my mentor teaches and assesses different classes. To see it in action is a totally different thing." PST B reported: "PK is very much a personal development in the classroom”. However, Tondeur et al. (2017) again commented that examples provided "in a specific educational context ... and discussing and reflecting on the successful uses of technology” (p. 48) are more likely to achieve better preparation for PSTs.

In contrast, PST AD found: "ICT was not used a great deal on my prac”. While PST AM commented: "My mentor teacher wouldn't use technology as she was older and not familiar with such technologies and preferred not to use them in class as they were unreliable". Another negative comment came from PST AK who suggested: “The problem is that it takes time and it doesn't always work in schools". PSTs acknowledged a concern about the digital divide especially when comparing private and public schools in terms of "the socioeconomic/resource boundaries" (PST AL). Such observations by PSTs have raised a level of conscientiousness in terms of not only the use of the technology but other socioeconomic factors 
related to access and use of technology in teaching and learning. Effective preparation of PSTs for technology use requires role models, reflection, instructional design, collaboration, authentic experiences, and feedback (Tondeur et al., 2017). It is apparent that not all PSTs have had access to all of these elements either during their course experiences or while on professional experience.

In answering the research questions, the preservice teachers had a positive perception of the TPACK components and TPACK's value as part of the teaching, learning and assessment cycle in secondary classrooms. They also perceived that they still have significant ongoing learning needs to develop deep knowledge, understanding and application of TPACK in contemporary classrooms. However, the PSTs feel strongly that this will develop throughout their course work and professional experience and well as ongoing learning as a beginning teacher.

\section{Implications for practice}

Designing and facilitating robust learning in technology-enhanced environments is complex and complicated. It is apparent from this study that both in the PSTs course work and professional experiences, they need to have opportunities to engage with the TPACK constructs and to apply this framework in their practice. Reflecting on their experiences and outcomes help PSTs to refine and design the next learning experience that purposefully integrates technology. It is much more than identifying what technology to use. Rather, Harris, Mishra, and Koehler (2009, p. 395) argued:

Understanding that introducing new educational technologies into the learning process changes more than the tools used - and that this has deep implications for the nature of content-area learning, as well as the pedagogical approaches among which teachers can select - is an important and often overlooked aspect of many technology integration approaches used to date.

From the analysis of the data, four implications for practice are presented for teacher education programs. First, PSTs need to be open and willing to integrate technology using pedagogical approaches that support deep learning of the content. The TPACK framework provides a means to "illuminating what teachers need to know about technology, pedagogy, and content and their interrelationships” (Harris et al., 2009, p. 403). This framework "does not specify how this should be accomplished, recognizing that there are many possible approaches to knowledge development of this type” (Harris, Mishra, \& Koehler, 2009, p. 403). As such, PSTs need to be open and willing to try to pedagogical practices that integrate technology in ways that meaningful supports the learning of the content.

Second, as part of their future teaching practice, PSTs need to continue to work with the TPACK model to develop a deeper understanding of the different components and the impact it has on their own practice. From the data, it was evident there was a misalignment between the PSTs understanding and that of the definitions and descriptions found in the literature. One of the critiques of the TPACK model according to Graham (2011) is that it "is easy to understand at a surface conceptual level” (p. 1955). However, there is difficulty in understanding the complexity of the constructs given the "fuzzy boundaries" (Graham, 2011, p. 1955). According to Angeli and Valanides (2009), the boundaries between some components of TPACK such as "what they define as Technological content knowledge and Technological pedagogical knowledge, are fuzzy indicating a weakness in accurate knowledge categorization or discrimination, and, consequently, a lack of precision in the framework" (p. 157). Given this lack of clarity in the defining of the boundaries, it can be problematic with PSTs who are just learning to apply the model. As they continue to work with the model in their practice, it will be important to see if they develop a deeper understanding and are able to articulate the components.

Third, purposeful integration, along with ongoing professional conversations, about of TPACK should be an integral component of the practicum experience. For secondary PSTs professional experience placement provides enhanced opportunities for them to view and practice discipline specific examples of technology integration when compared to the university courses. It also aligns with the concept that professional learning in TPACK “should be practice-based and personalised” (Harris \& Hofer, 2017, p. 11). The professional experience placement provides a forum for mentor teachers and teacher educators to collaborate to support PSTs in developing their TPACK understanding. According to Mishra and Koehler (2006) each component of the TPACK model should be well understood individually as well as in 
conjunction. Acquiring such knowledge can be taken up in the professional experience placements. It provides a forum for mentor teachers and faculty educators to collaborate in support PSTs in developing this understanding. Not only is it about integrating the technology in relation to the pedagogical purpose, it is also about assessing its impact. Through the debrief conversations as part of practicum, it provides a learning space for the PST and mentor teacher and/or teacher educator to talk about the experience and next steps through the lens of TPACK.

Fourth, teacher educators need to be role models in how TPACK is demonstrated to PSTs and to provide opportunities for the PSTs to use technology in teaching and learning. For example, teacher educators can role model such practice and provide meta-teaching moments to unpack what and why they have used such a practice. This provides more concrete examples for PSTs in their courses. Tondeur et al. (2017) also suggested that teacher educators should act as role models and assist PSTs to interpret the TPACK examples they see. Care needs to be given to how TPACK can be purposefully integrated. For example, are PSTs given opportunities to think about what technology they will use for an activity, and why it is better than another in terms of achieving the learning outcomes? Such experiences will help PSTs to be more intentional in how they design and facilitate learning within technology enhanced learning environments in their professional experience settings.

\section{Limitations and future research}

This study collected data from a small sample of PST participants in one course at one regional university. These results may not be generalisable to all PSTs within the program or country. Future research could replicate the study other courses and other universities. With additional implementation of this study it would establish a larger data set to provide greater insight into the PSTs' perceptions about TPACK. It would also be useful for international large-scale collaborative research that explores the pedagogical practices by PSTs, mentor teachers, and teacher educators.

\section{Conclusion}

From the study, it was evident the PSTs had a positive attitude towards TPACK and welcomed the opportunity to further develop their knowledge and skills for technology integration. They came to understand how purposeful integration of technology enhances student learning experiences. The PSTs were open to embracing the implementation of TPACK in their practice. With that said, PSTs also appreciated the need for ongoing professional development to support their ability to effectively implement TPACK in their practice. The TPACK model provides an approach "to examine a type of knowledge that is evident in teachers' practice when they transform their own understanding of subject matter into instruction in which technology and pedagogies support students' understanding and knowledge creation" (Kinuthia, Brantley-Dias, \& Clarke, 2010, p. 647)

The TPACK framework provides a model for teachers, pre-service teachers, teacher educators, and researchers to explore the messiness and complexity of technology integration in contemporary learning environments. It provides a framework to interrogate when and how technology can be used, as well as a means for transforming teaching, learning, and learning environments. PSTs who inform their practice using the TPACK model, will have a greater understanding of how to navigate the complexity of ICT integration to create robust and meaningful learning for students.

\section{References}

Angeli, C., \& Valanides, N. (2009). Epistemological and methodological issues for the conceptualization, development, and assessment of ICT-TPCK: Advances in technological pedagogical content knowledge (TPCK). Computers \& Education, 52(1), 154-168. https://doi.org/10.1016/j.compedu.2008.07.006

Florida Center for Instructional Technology (2005-2018). The technology integration matrix. Retrieved from https://fcit.usf.edu/matrix/matrix/

Graham, C. R. (2011). Theoretical considerations for understanding technological pedagogical content knowledge (TPACK). Computers \& Education, 57(3), 1953-1960. https://doi.org/10.1016/j.compedu.2011.04.010 
Green, L. S. (2014). Through the looking glass: Examining technology integration in school librarianship. Knowledge Quest, 43(1), 36-43.

Harris, J. B., \& Hofer, M. J. (2011). Technological pedagogical content knowledge (TPACK) in action: A descriptive study of secondary teachers' curriculum-based, technology-related instructional planning. Journal of Research on Technology in Education, 43(3), 211-229. https://doi.org/10.1080/15391523.2011.10782570

Harris, J. B., \& Hofer, M. J. (2017). “TPACK Stories”: Schools and school districts’ repurposing a theoretical construct for technology-related professional development. Journal of Research on Technology in Education, 49(1-2), 1-15. https://doi.org/10.1080/15391523.2017.1295408

Harris, J., Mishra, P., \& Koehler, M. (2009). Teachers' technological pedagogical content knowledge and learning activity types: curriculum-based technology integration reframed. Journal of Research on Technology in Education, 41(4), 393-416. https://doi.org/10.1080/15391523.2009.10782536

Hilton, J. T. (2016). A case study of the application of SAMR and TPACK for reflection on technology integration into two social studies classrooms. The Social Studies, 107(2), 68-73. https://doi.org/10.1080/00377996.2015.1124376

Hofer, M., \& Grandgenett, N. (2012). TPACK development in teacher education: A longitudinal study of preservice teachers in a secondary MA Ed. program. Journal of Research on Technology in Education, 45(1), 83-106. https://doi.org/10.1080/15391523.2012.10782598

Hughes, J. (2005). The role of teacher knowledge and learning experiences in forming technologyintegrated pedagogy. Journal of Technology and Teacher Education, 13(2), 277-302.

Hughes, J., Thomas, R., \& Scharber, C. (2006). Assessing technology integration: The RAT-replacement, amplification, and transformation-framework. In C. Crawford, R. Carlsen, K. McFerrin, J. Price, R. Weber, \& D. Willis (Eds.). Proceedings of the Society for Information Technology \& Teacher Education International Conference (pp. 1616-1620). Orlando, FL: Association for the Advancement of Computing in Education (AACE).

Jang, S.-J. (2010). Integrating the interactive whiteboard and peer coaching to develop the TPACK of secondary science teachers. Computers \& Education, 55(4), 1744-1751. https://doi.org/10.1016/j.compedu.2010.07.020

Kaufman, K. (2015). Information communication technology: Challenges \& some prospects from preservice education to the classroom. Mid-Atlantic Education Review, 2(1), 1-11.

Kinuthia, W., Brantley-Dias, L., \& Clarke, P. A. J. (2010). Development of pedagogical technology integration content knowledge in preparing mathematics preservice teachers: The role of instructional case analyses and reflection. Journal of Technology and Teacher Education, 18(4), 645-669.

Koh, J. H. L., Chai, C. S., \& Tsai, C.-C. (2010). Examining the technological pedagogical content knowledge of Singapore pre-service teachers with a large-scale survey. Journal of Computer Assisted Learning, 26(6), 563-573. https://doi.org/10.1111/j.1365-2729.2010.00372.x

Koehler, M. J., \& Mishra, P. (2005a). What happens when teachers design educational technology? The development of technological pedagogical content knowledge. Journal of Educational Computing Research, 32(2), 131-152. https://doi.org/10.14742/ajet.282

Koehler, M. J., \& Mishra, P. (2005b). Teachers learning technology by design. Journal of Computing in Teacher Education, 21(3), 94-102.

Koehler, M. J., \& Mishra, P. (2009). What is technological pedagogical content knowledge (TPACK)? Contemporary Issues in Technology and Teacher Education, 9(1), 60-70.

Lincoln, Y. S., \& Guba, E. G. (1985). Naturalistic inquiry. London: SAGE Publications.

Loughran, J., Mulhall, P., \& Berry, A. (2004). In search of pedagogical content knowledge in science: Developing ways of articulating and documenting professional practice. Journal of Research in Science Teaching, 41(4), 370-391. https://doi.org/10.1002/tea.20007

Mishra, P., \& Koehler, M. J. (2006). Technological pedagogical content knowledge: a framework for teacher knowledge. Teachers College Record, 108(6), 1017-1054.

Mishra, P., \& Koehler, M. J. (2008). Introducing technological pedagogical content knowledge. Proceedings of the Annual meeting of the American Educational Research Association, New York, NY. Retrieved from http://punya.educ.msu.edu/presentations/AERA2008/MishraKoehler_AERA2008.pdf

Puentedura, R. (2014, January 1). SAMR: A contextualized introduction [Blog post]. Retrieved from http://www.hippasus.com/rrpweblog/archives/2014/01/15/SAMRABriefContextualizedIntroduction.pdf

Redmond, P., \& Brown, K. (2004). Are we there yet? The journey of ICT integration. In R. Ferdig, C. Crawford, R. Carlsen, N. Davis, J. Price, R. Weber, \& D. Willis (Eds.). Proceedings of Society for Information Technology \& Teacher Education International Conference 2004 (pp. 1001-1008). Chesapeake, VA: AACE. 
Ryan, G. W., \& Bernard, H. R. (2003). Techniques to identify themes. Field methods, 15(1), 85-109. https://doi.org/10.1177/1525822X02239569

Shulman, L. (1986). Those who understand: Knowledge growth in teaching. Educational Researcher, 15(2), 4-14.

Starkey (2010) Teachers’ pedagogical reasoning and action in the digital age. Teachers and Teaching, 16(2), 233-244. https://doi.org/10.1080/13540600903478433

Tondeur, J., Scherer, R., Siddiq, F., \& Baran, E. (2017). A comprehensive investigation of TPACK within pre-service teachers’ ICT profiles: Mind the gap! Australasian Journal of Educational Technology, 33(3), 46-60. https://doi.org/10.14742/ajet.3504

Valtonen, T., Sointu, W., Kukkonen, J., Kontkanen, S., Lambert, M., \& Mäkitalo-Siegl, K. (2017). TPACK updated to measure pre-service teachers' twenty-first century skills. Australasian Journal of Educational Technology, 33(3), 15-31. https://doi.org/10.14742/ajet.3518

Wozney, L., Venkatesh, V., \& Abrami, P. C. (2006). Implementing computer technologies: Teachers' perceptions and practices. Journal of Technology and Teacher Education, 14(1), 173-207.

Corresponding author: Petrea Redmond: redmond@usq.edu.au

Australasian Journal of Educational Technology (C) 2019.

Please cite as: Redmond, P., \& Lock, J. (2019). Secondary pre-service teachers’ perceptions of technological pedagogical content knowledge (TPACK): What do they really think? Australasian Journal of Educational Technology, 35(3), 45-54. https://doi.org/10.14742/ajet.4214 